\title{
Implementasi Pendidikan Karakter Berdasarkan Nilai Pancasila di Era Globalisasi
}

\author{
Lin Herlina $^{1 *}$, Dinie Anggraeni Dewi ${ }^{2}$ \\ 1,2 Univeritas Pendidikan Indonesia, Indonesia \\ *email: linherlina219e@upi.edu
}

\begin{abstract}
Abstrak: Pendidikan karakter merupakan salah satu hal penting bagi kehidupan bangsa Indoneisa. Pancasila dijadikan sebagai dasar negara, sekaligus juga merupakan ideologi negara. Selain itu pancasila juga merupakan way of life bangsa indonesia. Dengan perkembangan teknologi yang semakin pesat maka percepatan globalisasi pun demikian. Artikel ini akan menjabarkan implementasi nilai pancasila yang harus diterapkan agar nilai-nilai pancasila tetap kokoh maka diperlukan pengukuhan nilai-nilai pancasila tersebut kepada generasi penerus bangsa khususnya kepada para peserta didik dari jenjang sekolah dasar hingga ke jenjang perguruan tinggi. Hal tersebut dapat diupayakan dengan mempelajari mengenai kewarganegaraan dan juga pancasila. Metode kualitatif pengumpulan data-data melalui kajian pustaka dengan sumber dari berbagai daterasi yang terdapat kajian mengenai pengimplementasian nilai pancasila di era globalisasi seperti dalam buku, artikel, dan jurnal. Kesimpulan dari semua elemen berperan untuk mengokohkan nilai-nilai dasar yang terkandung dalam pancasila karena hal tersebut merupakan karakter bangsa Indonesia. Dengan demikian setiap elemen diharapkan dapat memberikan contoh teladan yang baik bagi generasi mudanya agar dapat menciptakan generasi muda yang berkepribadian sesuai dengan nilai-nilaipancasila sehingga generasi mudanya dapat mempertahankan budaya dan kepribadian jiwa bangsa Indonesia.
\end{abstract}

\section{Kata Kunci: Implementaso, Globalisasi, Pancasila}

\begin{abstract}
Character education is one of the important things for the life of the Indonesian nation. Pancasila is used as the basis of the state, as well as the state ideology. In addition, Pancasila is also a way of life for the Indonesian nation. With the rapid development of technology, the acceleration of globalization is also the same. This article will describe the implementation of Pancasila values that must be applied so that Pancasila values remain strong, it is necessary to strengthen these Pancasila values to the next generation of the nation, especially to students from elementary school to university level. This can be pursued by learning about citizenship and Pancasila. The qualitative method of collecting data is through a literature review with sources from various dates where there are studies on the implementation of Pancasila values in the era of globalization such as in books, articles, and journals. The conclusion of all elements plays a role in strengthening the basic values contained in Pancasila because this is the character of the Indonesian nation. Thus, each element is expected to provide a good example for the younger generation in order to create a young generation with a personality in accordance with Pancasila values so that the younger generation can maintain the culture and personality of the Indonesian nation.
\end{abstract}

Keyword: implementation, Globalization, Pancasila

Copyright (c) 2021 The Authors. This is an open access article under the CC BY-SA 4.0 license (https://creativecommons.org/licenses/by-sa/4.0/) 


\section{PENDAHULUAN}

Pendidikan karakter merupakan salah satu upaya untuk meminimalisir dampak negatif dari pengaruh globalisasi. Hasibuan et al., (2018) menyatakan bahwa pendidikan karakter telah menjadi bagian penting dapam kehidupan. Dengan adanya pancasila merupakan hal penting bagi kehidupan bangsa Indoneisa, pancasila dijadikan sebagai dasar negara dan juga merupakan ideologi negara. Selain itu pancasila juga merupa way of life bangsa indonesia. Pancasila yang dipahami sebagai pedoman hidup bangsa memiliki makna yang lebih luas, pancasila merupakan nilai luhur yang harus dipahami dan dilaksanakan dalam kehidupan berbangsa dan bernegara.

Pancasila sendiri telah dikenal sejak masa kerajaan majapahit. Secara etimologis pancasila berasal dari bahasa sansekerta yang berarti lima dasar. Dalam Buku Konsep dasa PKn yang ditulis oleh Prof. Sapriya (2011) menyebutkan bahwa di dalam buku sutasoma terdapat dua arti yaitu yang berbatu sendi yang lima dan pelaksanaan kesusilaan yang lima. Kelima kesusilaan tersebut adalah (1) tidak boleh melakukan kekerasan, (2) tidak boleh mencuri, (3) tidak boleh berjiwa dengki, (4) tidak boleh berbohong, dan (5) tidak mabuk minuman keras. Dalam buku tersebut juga disebutkan bahwa pancasila yang sekarang menjadi dasar negara berarti lima nilai dasar. Pancasila merupakan dasar negara yang jika diibaratkan pancasila merupakan pondasi dari berdirinya bangsa Indonesia. Pancasila juga mencerminkan kepribadian yang apabila di implementasikan dengan sungguh-sungguh akan mencerminkan kepribadian bangsa indonesia. pancasila juga sebagai ideologi nasional, yang berarti bahwa pancasila memiliki nilai yang juga menjadi citacita negara. Ir. Soekarno menyatakan bahwa pancasila sebagai jiwa yang bersifat turun temurun. Pancasila bukan hanya falsafah negara pancasila leih dari sekedar falsafah negara (lubis \& nasution, 2019).

Dalam pancasila tidak bersifat kaku dan tertutup melainkan pancasila sebagai ideologi bersifat bergerak atau dinamis, aktual, antisipatif dan mampu menyesuaikan dengan perkembangan zaman (Ariawantara, 2017). Ideologi 
pancasila tidak menjadikan pancasila sendiri menjadi ketinggalan zaman namun, bukan berarti zaman dapat merubah nilai dasar yang telah diperkuat sejak 1 juni 1945 pada sidang BPUPKI dan tercantum dalam pembukaan undang-undang Dasar 1945 berdasarkan Keputusan PPKI.

Untuk itu pada aspek pendidikan yang ada di indonesia diterapkan Pendidikan Pancasila dan juga Pendidikan Kewarganegaraan yang bertujuan untuk menumbuhkan karakter pancasila dalam diri generasi mudanya dan senantiasa menerapkan nilai-nilai pancasila dalam kehidupan sehari-hari sejak usia dini. Hal tersebut dikarenakan perkembangan zaman yang terus berlangsung sehingga tidak sedikit anak-anak yang mulai mengabaikan nilainilai pancasila tersebut dalam kehidupan sehari-harinya. Hartono et al., (2016) menyatakan bahwa dalam proses pendidikan titik beratnya terletak pada pihak peserta didik sehingga proses pembelajaran menjadi proses interaksi dengan pengalaman-pengalaman baru yang ia alami.

Globalisasi membawa tantangan tersendiri bagi nilai-nilai pancasila dan juga bangsa Indonesia. Tidak hanya membawa pengaruh positif dalam kehidupan bangsa globalisasi juga, membawa perubahan yang negatif bagi bangsa Indonesia. Pertukaran kebudayaan yang mengakibatkan anak-anak mudanya menjadi lebih tertarik kepada budaya tersebut menjadikan budaya tersebut diterapkan ke dalam kehidupan sehari-harinya dan melupakan budaya negaranya sendiri sehingga lambat laun budaya tersebut akan hilang tergerus oleh zaman. Generasi muda sekarang lebih cenderung mencontoh hal yang bersifat negatif. Akibatnya mereka menjadi pribadi yang tidak mengedepankan nilai jati diri bangsa. Kelangsungan hidup di era globalisasi ini mengharuskan kita untuk tetap mengupayakan penerapan atau pengimplementasian nilai pancasila dalam kehidupan sehari-hari. Agar eksistensi nilai pancasila tetap terjada dan generasi yang akan datang tetap dapat mengamalkan nilai luhur pancasila dalam kehidupannya.

\section{METODE PENELITIAN}


Dalam pengumpulan data penulis menggunakan metode kualitatif dengan cara kajian puska. Penelitian kualitatif merupakan data yang berupa kata-kata yang dimulai dengan fakta, realita, dan gejala, dan masalah yang diperoleh (Sugiyono p d, 2013). Somantri dalam Lauder et al., (2002) juga menyatakan bahwa penelitian kualitatif merupakan tempat yang terbuka luas untuk berdiskusi ilmu dengan latar belakanh yang berbeda. Penelitian ini dilakukan dengan cara pengumpulan data dari sumber yang berkaitan dengan mesalah, kemudian sumber di klasifikasikan dan di baca untuk memperoleh data yang diinginkan, kemudian data di analisis.

\section{HASIL dan PEMBAHASAN}

Globalisasi merupakan suatu hal yang tidak dapat dihindari keberadaanya termasuk di Indonesia globalisasi juga tetap terjadi dari waktu ke waktu. Dengan perkembangan teknologi yang semakin pesat maka percepatan globalisasipun demikian. Agar nilai-nilai pancasila tetap kokoh maka diperlukan pengokohan nilai-nilai pancasila tersebut kepada generasi penerus bangsa khususnya kepada para peserta didik dari jenjang sekolah dasar hingga ke jenjang perguruan tinggi. Hal tersebut dapat diupayakan dengan mempelajari mengenai kewarganegaraan, juga pancasila, dan pendidikan karakter.

Hal tersebut telah dilakukan diberbagai jenjang pendidikan dengan dimuatnya mata pelajaran Pendidikan Kewarganegaraan (PKn),juga pendidikan pancasila, dan pendidikan karakter. Karena menurut Dariatun Daryanto pendidikan karakter dapat menumbuhkan sikap bangsa yang tangguh, bermoral, bertoleran, berakhlak mulia, berjiwa politik, yang berorientasi pada pengetahuan teknologi yang semuanya dijiwai oleh keimana dan ketakwaan kepada tuhan Yang Maha Esa berdasarkan pancasila dan kertuhana Yang Maha Esa (Purwanti, 2017). Tidak hanya dilingkungan sekolah saja. untuk mengokohkan nilai-nilai pancasila juga dapat dilakuakan dari lingkungan keluarga dan juga lingkungan masyarakat. Semua elemen harus dapat berkolaborasi agar nilai-nilai pancasila tetap kokoh. 
keluarga berperan untuk memberikan contoh yang baik seperti beribadah sesuai kepercayaan, menghargai perbedaan, menghargai jasa para pahlawan yang telah berjuang mempertaruhkan nyawanya, memberi pengawasan kepada anak agar anak tidak terjerumus kepada hal-hal yang negatif, menggunakan produk dalam negri dan merasa bangga terhadap produk yang di produksi di dalam negri. Pendidikan disekolah juga harus menekankan pada penerapan nilai-nilai pancasila yang teladi pelajari memalui Pendidikan Pancasila dan Pendidikan Kewarganegaraan (P3Kn). Selain itu sekolah juga harus menanamkan nilai toleransi dan cinta terhadapt tanah air, sekolah juga berkewajiab untuk memberikan pendidikan moral agar para murid tidak menyerap hal yang negatif dari adanya globalisasi yang dapat mengancam ketahanan bangsa Indonesia. karena dalam kenyataannya banyak peserta didik yang terjerumus kedalam hal-hal yang negatif seperti salah bergaul, narkoba, minuman keras, seks bebas, dan hal negatif lainnya yang tidak sesuai dengan kepribadian bangsa Indonesia.

Menurut adi menyatakan bahwa sila-sila dalam pancasila merupakan satu seksatuan organisme (Winataputra, 2016). Sila ketuhanan Yang Maha Esa merupakan perwujudan dari jiwa keagmaan, sila kemanusiaan yang adil dan beradab merupakan jiwa yang berperikemanusiaan, sila persatuan indonesia merupakan perwujudan jiwa kebangsaan, sila kerakyatan yang di pimpin oleh hikmat kebijaksanaan dalam permusyawaratan/perwakilan merupakan perwujudan dari jiwa kemanusiaan, dan sila keasilan sosial bagi seluruh rakyat indonesia merupakan perwujudan atas jiwa yang menjunjung tingi rasa keadilan. Perwujudan tersebut yang harus selalu tercermin dalam kehidupan bangsa indonesia. menurut kalidjenih menyebutkan bahwa pada hakekarnya semua sila dalam pancasila yang menjalankan adalah manusia (Kalidjernih, Dkk. 2019).

Sila pertama yang berbunyi "Ketuhana Yang Maha Esa", sila pertama merupakan kekuatan antara individu dengan tuhannya, individu dengan semesta yang lebih luas dan menyediakan makna. Di dalamnya terdalat apresiasi terhadap keindahan, rasa syukur, harapan, dan nilai religius. Dalam 
pengimplementasian pada sila ini dapat dilakukan dengan memperkuat hubungan dengan tuhan dengan cara beribadah sesuai agamanya masingmasing, selain itu menjalin toleransi dan hubungan saling menghormati antar umat beragama agar tidak terjadi Intoleransi yang dapat menimbulkan perpecahan. Bertakwa kepada tuhan merupakan salah satu cara untuk menghindarkan diri dari hal-hal negatif. Nilai ketuhanan dianggap penting untuk dijadikan landasan kehidupan dan landasan dalam bernegara sebagaimana yang telah tercantum dalam sila pertama pancasila (Kariyadi \& Suprapto, 2017)

Sila kedua yang berbunyi "Kemanusiaan yang adil dan beradab", sila kedua ini lebih menekankan pada nilai kemanusiaan dan hubungan antara individu yang satu dengan yang lainnya. Dapat di implementasikan dengan mencintai satu sama lain sebagai makluk ciptaan tuhan, saudara sebangsa. Menghormati hak-hak yang dimiliki oleh setiap orang agar tidak terjadi pelanggaran hak seseorang, tolong menolong dengan sesama. Semua warga negara memiliki kesamaan hak dalam memperoleh kesejahteraan sosial, penghidupan yang layak, persaan hak dalam berpolitik, kesetaraan Hukum, tanpa melihat perbedaan suku dan ras.

Sila ketiga yang berbunyi "Persatuan Indonesia". menururt meinarno sila ketiga ini berusaha dicapai dengan penggunaan Bahasa Indonesia sebagai bahasa pemersati (Kariyadi \& Suprapto, 2017). dalam kehidupan bermasyarakat manusia pasti akan bertemu dengan manusia lainnya dari berbagai golongan, suku, dan juga ras. Manusia pasti akan berhubungan dengan satu sama lain. Dalam hubungan tersebut pasti akan ada tujuan-tujuan dari masing-masing individu. Dengan sadanya sila ini perbedaan-perbedaan tersebut disatukan oleh Bhineka Tunggal Ika. Perbedaan merupakan anugerah yang diberikan oleh tuhan Yang Maha Esa yang harus disyukuri keberadaannya karena keberagaman dan perbedaan menjadikan negara indonesia yang kaya akan budaya. Perbedaan seharusnya bukan hal yang memicu konflik dan mengakibatkan perpecahan, perbedaan haruslah menjadi pengikat dan menjadi salah satu hal yang saling menguntungkan satu sama 
lain persatuan dalam kehidupan untuk mewujudkan tujuan nasional. Dengan adanya rasa persatuan ini akan memperkecil terjadinya disintegrasi bangsa.

Sila keempat yang berbunyi "Kerakyatan yang dipimpin oleh hikmat kebijaksannan dalam permusyawaratan/perwakilan”. Kariyadi \& Suprapto, (2017) menyatakan bahwa sila ke empat ini mengandung nilai tanggung jawab dan harmoni yang merupakan nilai kental dari bangsa indonesia sebagai negara demokrasi. Indonesia merupakan negara yang demokrasi dalam setiap pengambilan keputusan dilakukan dengan cara melakukan musyawarah oleh karena itu dalam mengeluarkan kebijakan seseorang maupun pemerintah tidak boleh hanya untuk menguntungkan dirinya sendiri. Dengan kata lain setiap kebijakan yang dikeluarkan haruslah menguntungkan bagi masyarakat atau orang banyak. Meningkatkan nilai kekeluargaan dan nilai gotong royang. Dengan adanya nilai-nilai tersebut akan mudah untuk menggapai tujuan nasional.

Sila kelima "Keadilan sosial bagi seluruh rakyat Indonesia", sila ini erat kaitannya dengan rasa adil bukan hanya untuk seseorang malainkan untuk seluruh masyarakar Indonesia. Basuki (2019) menyatakan bahwan pembuatan kategori ini merupakan dampak logis dari tidak terbentuknya salah satu kontruk pancasila yang diperkirakan sebelumnya yang menjadi cita-cita bangsa Indonesia adalah keadilan sosial bagi seluruh rakyatnya. Rakyat Indonesia berhak untuk mendapatkan penghidupan yang layak, kesetaraan kesejateraan sosial, penghormatan HAM, dan mendapatkan hakhak yang sama. Menjaga keseimbangan antara menuntut hak dan menjalankan kewajiban menjadi salah satu cara untuk menjalankan sila tersebut dengan demikian tidak akan terjadi kesenjangan antara hak dan juga kewajiban.

Di era globalissi seperti ini menanamkan sikap nasionalisme juga dirasa sangat penting untuk menjaga semangat para generasi muda. Terdapat beberapa cara untuk meningkatkan rasa nasionalisme dengan cara (1) menghormati dan mencinta para pahlawan dengan cara mengenang perjuangan-perhuangan yang telah dilakan oleh beliau untuk merebut 
kemerdekaan dari tangan penjajahan. (2) menjadi pribadi yang baik dan berperilaku sesuai dengan nilai-nilai yang terkandung dalam pancasila. (3) mejaga kebudayaan-kebudayaan yang ada di Indonesia dengan tetap melestarikannya dan juga menggunakan produk-produk yang diproduksi di dalam negeri. (4) menghilangkan pemikiran etnosentris dalam bermasyarakat, karna bangsa yang multikultural harus dapat menerima setiap perbedaan yang ada (5) memilah dan memilih budaya-budaya asing yang masuk kedalam negeri.

Dari sikap-sikap tersebut terdapat beberapa karakter yang ingin dicapai oleh bangsa indoneisa (1) masyarakat yang bertakwa kepada tuhan Yang Maha Esa pada agama dan tuhannya masing-masing, (2). Masyarakat sadar akah hak-hak dan kewajibanya sebagai waeganegara, masyarakat, anggota keluarga, dan sebagai pribadinya, (3). Mampu menempatkan dirinya sesuai dengan tempatnya, (4). Mampu menjalankan kewajiban-kewajibannya sesuai dengan perundang-undangan yang berlaku, dan mampu berhubungan baik dengan sesama warga negar, (5). Mampu menjadi generasi yang memahami perannya untuk menciptakan kesejahteraan pada generasi selanjutnya.

Soeprapto (2005) menyatakan dalam artikelnya bahwa prinsip-prinsip tersebut merupakan prinsi-orinsip yang sangan diinginkan di seluruh dunia prisip kehidupan universal seperti religius, nasionalitas, humanitas, sovereinitas, dan sosialitas yang dihubungkan dengan keadaan lingkungan masing-masing dengan tantangan dan keadaan zaman yang berbeda-beda. Keyakinan nasional atas dasar negara merupakan sebagai benteng untuk menghadapi tantangan di era globalisasi ini. Pancasila sebagai identitas dan kpribadian bangsa indonesia merupakan sebuah sumber hidup, motivasi,. Pancasila harus mampu menyaring tantangan-tantangan dari globalisasi yang mampu membawa perubahan negatif. Tantanga globalisasi terhadap pancasila ini dapat mengancam eksistensi kepribadian bangsa Indonesia. Kini bangsa Indonesia tengah berada dalam arus globalisasi dunia yang sudah tidak dapat dipungkiri lagi. Dengan demikian kita harus memperkokoh nilai- 
nilai pancasila dan mengamalkannya dalam kehidupan sehari-hari agar bangsa indonesa tidak kehilangan jati dirinya.

Upaya untuk memperkokoh nilai-nilai pancasila dengan memahami dan mendalami konsep nilai-nilai yang terkandung dalam pancasila dapat menjadi salah satu upaya untuk memperkokoh nilai-nilai pancasila di era globalisasi. Selain itu ia juga menyebutkan bahwa menyusun pola implementasi yang berupa stategi, sistem dan stuktur dalam penyelenggaraan implementasi juga dapat menjadi salah satu cara lain untuk memperkokoh nilai pancasila dalah kehidupan di era globalisasi ini.

\section{SIMPULAN}

Pancasila merupakan salah satu hal penting bagi kehidupan bangsa Indoneisa. Pancasila dijadikan sebagai dasar negara,pancasila juga merupakan ideologi negara. selainitu pancasila juga merupa way of life bangsa indonesia. pancasila serangkaian nilai-nilai yang mendasar. Glabalisasi yang keberadaannya tidak dapat dipungkiri lagi menjadikan nilainilai pancasila mulai luntur dalam kehidupan generasi muda bangda indonesia. untuk itu kita perlu memperkokoh kembali nilai-nilai pancasila kepada generasi muda bangsa Indonesia. dalam mengokohkan nilai-nilai pencasila ini memerlukan kolaborasi dari seluruh elemen baik dari lingkungan keluarga ,lingkungan masyarakat, maupun lingkungan sekolah. Pengimplementasian nilai pancasila di era globalisasi ini diantaranya dengan memperkuat keimanan dan ketakwaan kepada tuhan agar tidak terjerumus kedalam hal-hal yang negatif, menghargai perbedaa, menjunjung tinggi nilainilai kekeluargaan dan nilai gotong royang, juga menanamkan raca nasionalisme. Keyakinan nasional atas dasar negara merupakan sebagai benteng untuk menghadapi tantangan di era globalisasi ini sealin itu memahami dan mendalami nilai-nila yang terdapat dalam pancasila juga merupakan suatu upaya untuk memperkokoh nilai-nilai pancasila dalam kehidupan di era globalisasi ini

Ditarik dari kesimpulan semua elemen berperan untuk mengokohkan nilainilai dasar yang terkandung dalam pancasila karena hal tersebut merupakan 
karakter bangsa Indonesia. Dengan demikian setiap elemen diharapkan dapat memberikan contoh teladan yang baik bagi generasi mudanya agar dapat menciptakan generasi muda yang berkepribadian sesuai dengan nilainilaipancasila sehingga generasi mudanya dapat mempertahankan budaya dan kepribadian jiwa bangsa Indonesia.

\section{DAFTAR RUJUKAN}

Ariawantara, P. 2017. Implementasi Pancasila Dalam kehidupan Berbangsa dan Bernegara. Universitas Airlangga.

Basuki, K. (2019). No Title No Title. ISSN 2502-3632 (Online) ISSN 23560304 (Paper) Jurnal Online Internasional \& Nasional Vol. 7 No.1, Januari - Juni 2019 Universitas 17 Agustus 1945 Jakarta, 53(9), 16891699. www.journal.uta45jakarta.ac.id

Hartono, W., Ekstrinsik, M., \& Belajar, K. (2016). Dyah Ayu Puspitaningrum. 6(2), 25-30.

Hasibuan, A. A., Syah, D., \& Marzuki, M. (2018). Manajemen Pendidikan Karakter Di Sma. Tarbawi: Jurnal Keilmuan Manajemen Pendidikan, 4(02), 191. https://doi.org/10.32678/tarbawi.v4i02.1230

Kariyadi, D., \& Suprapto, W. (2017). Membangun Kepemimpinan Berbasis Nilai-Nilai Pancasila Dalam Perspektif Masyarakat Multikultural. Citizenship Jurnal Pancasila Dan Kewarganegaraan, 5(2), 86. https://doi.org/10.25273/citizenship.v5i2.1560

Lauder, M. R. M. T., Nusantara, U. B., \& Lauder, M. R. M. T. (2002). Makara Human Behavior Studies in Asia. 6(1), 37-44.

lubis, R., \& nasution, J. iqbal. (2019). Makalah ppkn kelompok 3. https://doi.org/10.31219/osf.io/ys6e4

Purwanti, D. (2017). Pendidikan Karakter Peduli Lingkungan Dan Implementasinya. DWIJA CENDEKIA: Jurnal Riset Pedagogik, 1(2), 14-20. https://doi.org/10.20961/jdc.v1i2.17622

Sapriya, Dkk. 2001. Konsep Dasar Pendidika Kewarganegaraan Edisi Revisi. Laboratorium Universitas Pendidikan Indonesia.

Soeprapto. (2005). 22960-44318-1-SM.pdf. Implementasi Pendidikan Karakter Berdasarkan Nilai Pancasila Di Era Globalisasi 
377 | Jurnal Pendidikan dan Kewirausahaan Vol. 9 No. 22021

https://jurnal.ugm.ac.id/jkn/article/view/22960

Sugiyono p d. (2013). Metode Penelitian Kuantitatif. Alfabeta.

Winataputra, U. S. (2016). Jurnal moral kemasyarakatan vol. 1, no.1, juni 2016. Jurnal Moral Kemasyarakatan, 1(1), 15-36.

Implementasi Pendidikan Karakter Berdasarkan Nilai Pancasila Di Era Globalisasi 